American Journal of Pharmaceutical Education 2018; 82 (10) Article 7423.

\title{
COMMENTARY
}

\section{Teaching Innovation and Creativity, or Teaching to the Test?}

\author{
Nancy Fjortoft, PhD, ${ }^{\mathrm{a}, \mathrm{b}}$ Jacob Gettig, PharmD, MPH, ${ }^{\mathrm{a}}$ Melinda Verdone, MS, MAEd ${ }^{\mathrm{a}}$ \\ ${ }^{a}$ Midwestern University Chicago College of Pharmacy, Downers Grove, Illinois \\ ${ }^{\mathrm{b}}$ Associate editor, American Journal of Pharmaceutical Education
}

Submitted November 1, 2018; December 2, 2018; published December 2018.

Keywords: innovation, PCOA, NAPLEX, creativity

In a statement published in the American Journal of Pharmaceutical Education in 2012, Svensson and colleagues called for a number of changes to our academy. One of those changes was to "prepare students to be innovative and create nontraditional career paths." According to Merriam Webster, innovation is the introduction of something new, or a new idea, method or device. $^{2}$ Furthermore, we assert that it is the process of putting new ideas into practice; creative thinking is the foundation of innovation as well as entrepreneurship. In the recent review on entrepreneurship in pharmacy practice and education, Mattingly et al, cited creativity and innovation as the most important skills for entrepeneurship. ${ }^{3}$ Since that call for change in 2012, the Center for the Advancement of Pharmacy Education published new educational outcomes which included a domain called Personal and Professional Development, ${ }^{4}$ which draws largely from the Habits of Mind. ${ }^{5}$ In the Accreditation Council for Pharmacy Education (ACPE) "Standards 2016" document, standard 4 describes personal and professional development as having four key elements. One of those elements is innovation and entrepreneurship. "The graduate is able to engage in innovative activities by using creative thinking to envision better ways of accomplishing professional goals." As a result of the multi-year effort, colleges and schools of pharmacy are now required to develop and assess creative thinking abilities in their students.

Tips on teaching creativity abound on the internet. For example, in 30 Ideas to Promote Creativity in Learning, Miriam Clifford suggests developing assignments that use divergent and convergent thinking. Clifford explains that while education has long relied on testing analytical thinking leading to one right answer, divergent thinking assesses how students use different approaches to solving a problem. ${ }^{7}$ Much of this discussion has

Corresponding Author: Nancy Fjortoft, Midwestern University Chicago College of Pharmacy, $55531^{\text {st }}$ St., Downers Grove, IL 60515. Tel: 630-971-6417. E-mail: nfjort@midwestern. edu focused on K-12 and college education; however, there is an emerging call for creativity in medical and health sciences education. ${ }^{8}$ As health care organizations become increasingly complex, new diseases emerge, and public health issues arise, health professions need innovative and creative practitioners to develop new approaches and solutions to these problems. For example, the emerging field of precision medicine requires practitioners to use new frameworks to solve problems for individual patients, and to not rely on the one right answer for all. Since Standards 2016, pharmacy education is beginning to explore and describe teaching students to think creatively. Cain, in a recent article, describes an elective course that uses various techniques to teach creative thinking and innovation. The course design includes both live class sessions and online content, and it involves learning techniques such as brainstorming, solving puzzles, and problem solving. The nature of these teaching techniques require a small class size. Cain goes on to summarize how the educational system has suppressed creativity and has also taught students that there is only one right answer to a problem. On the other hand, teaching creativity, he argues, encourages sharing ideas and taking risks, and concedes that there may not be one right answer. ${ }^{9}$

Standards 2016 also calls for standardized and comparative assessments that allow for national comparisons and college or school determined peer comparisons. ${ }^{10}$ The guidelines go on to explain the use of PCOA, which "allows programs to benchmark student performance in retention of knowledge in required scientific domains." 10 In short, standardized exams are now required for admissions to many colleges of pharmacy (ie, PCAT), prior to beginning APPE rotations (ie, PCOA) and prior to entering practice (ie, NAPLEX and MPJE). PCOA scores and NAPLEX pass rates of colleges of pharmacy are monitored by ACPE.

A recent study examined school costs and motivations for providing NAPLEX and PCOA preparation and found that $80 \%$ of the 91 responding schools provided some form of NAPLEX preparation. These techniques ranged from providing question banks, live reviews, and mock exams, 


\section{American Journal of Pharmaceutical Education 2018; 82 (10) Article 7423.}

developed either by faculty or by independent vendors. ${ }^{11} \mathrm{~A}$ number of NAPLEX review courses exist, such as Kaplan, RxPrep, and High Yield. According to an email from Karen Shapiro, Clinical Pharmacist Educator and CEO of RxPrep in October 2018, 66 colleges and schools of pharmacy have contracted with RxPrep to provide the review course to all of their students. Another 28 colleges and schools of pharmacy provide RxPrep through student organizations, so it is available on a voluntary basis. About $20 \%$ of the respondents reported providing students with PCOA preparation using similar techniques. ${ }^{11}$ Another recent study on the use of PCOA found that a 24 of the 126 responding schools tied either participation or performance in PCOA to a course grade. ${ }^{13}$ Whether or not both of these activities are trending upward or will remain stable is not known, but these studies indicate that some colleges of pharmacy are spending time preparing students to perform well on these exams or "teaching to the test."

In a recent interview with The New York Times, Sir Ken Robinson, an international leader in education, provided comments on his long-standing criticism of standardized testing. He states "it's generated a dreary culture of incessant competition, which has soaked up billions of taxpayer dollars with no significant improvement in standards, causing enormous stress for teachers, children, and their families." ${ }^{14}$ Pharmacy students arrive at our colleges from these environments, and standardized testing continues. Are we too creating a "dreary culture" that can stifle creativity and innovation? Or, can colleges of pharmacy, within their curricula, effectively and efficiently teach innovation and creativity and teach to the test?

\section{REFERENCES}

1. Svensson CK, Ascione FJ, Bauman JL, et al. Are we producing innovators and leaders or change resisters and followers? Am J Pharm Educ. 2012;76(7):Article 124.
2. Merriam Webster. https://www.merriam-webster.com/dictionary/ innovation. Accessed October 25, 2018.

3. Mattingly, TJ, Mullins CD, Melendez DR, et al. Entrepreneurship in pharmacy practice and education: a systematic review. $\mathrm{Am} J$ Pharm Educ. https://www.ajpe.org/doi/abs/10.5688/ajpe7233. In press, 2018. Accessed October 26, 2018.

4. Medina MS, Plaza CM, Stowe CD, et al. Center for the advancement of pharmacy education 2013 educational outcomes. Am J Pharm Educ. 2013;77(8):Article 162.

5. Costa AL, Kallick B. Habits of Mind. https://www.chsvt.org/wdp/ Habits_of_Mind.pdf. Accessed October 31, 2018.

6. Accreditation Council for Pharmacy Education. Accreditation standards and key elements for the professional program in pharmacy leading to the doctor of pharmacy degree. Standards 2016. https:// www.acpe-accredit.org/pdf/Standards2016FINAL.pdf. Accessed October 25, 2018.

7. Clifford M. 30 ideas to promote creativity in learning. https:// www.teachthought.com/learning/30-ideas-to-promote-creativity-inlearning/. Accessed September 28, 2018.

8. Ness RB. Teaching creativity and innovative thinking in medicine and the health sciences. Acad Med. 2011;86(10):1201-1203.

9. Cain J. A pharmacy elective course on creative thinking, innovation, and TED talks. Am J Pharm Educ. 2016;80(10):Article 170.

10. Accreditation Council for Pharmacy Education. Guidance for the accreditation standards and key elements for the professional program in pharmacy leading to the doctor of pharmacy degree. Guidance for Standards 2016. https://www.acpe-accredit.org/ pdf/GuidanceforStandards2016FINAL.pdf. Accessed October 25, 2018.

11. Lebovitz L, Shuford VP, DiVall MV, Daugherty KK, Rudolph MJ. Creating an arms race? Examining school costs and motivations for providing NAPLEX and PCOA preparation. Am J Pharm Educ. 2017;81(7):Article 5909.

12. Sweet BV, Assemi M, Boyce E, et al. Characterization of PCOA use across accredited colleges of pharmacy. Am J Pharm Educ. In Press. https://doi.org/10.5688/ajpe7091. In Press, 2018. Accessed October 26, 2018.

13. Robinson, Sir Ken. An expert's view. The New York Times. Published April 5, 2018. https://www.nytimes.com/2018/04/05/ education/learning/an-experts-view-sir-ken-robinson.html. Accessed September 28, 2018. 